\section{A retrospective evaluation after insertion of the MicroGYNious single incision sling in cases of stress urinary incontinence}

\author{
Sabine Schütze, ${ }^{1}$ Ulf Göretzlehner, ${ }^{2}$ \\ Elisabeth Mian, ${ }^{1}$ Fabienne Schochter, ${ }^{1}$ \\ Wolfgang Janni, ${ }^{1}$ Miriam Deniz ${ }^{1}$ \\ ${ }^{1}$ Department of Gynaecology and \\ Obstetrics University UIm, Ulm; \\ ${ }^{2}$ Frauenklinik, Alb-Donau Klinikum, \\ Ehingen, Germany
}

\begin{abstract}
In the literature the rate of stress incontinence is reported between $29-75 \%$. Compared to the established tension free vaginal tapes, the question arises, whether stabilization of the urethra can also be achieved by minimally invasive single incision slings. The aim of this retrospective analysis is to evaluate the cure rate after insertion of MicroGYNious sling. The study was carried out on 115 patients, who received a MicroGYNious sling. It was used both as a single operation for stress urinary incontinence and as a combined procedure. The degree of incontinence preoperatively and continence rate postoperatively with follow-ups (6 weeks, 6 months, one year, two years and three years) were recorded. Due to a high number of lost to follow-up after one year, only the data up to one year postoperative were included in the analysis. Preoperatively, grade I incontinence was found in $6.1 \%$, grade II $35.7 \%$, grade III $58.3 \%$ of the operated women. The continence rate was $96.7 \%$ postoperatively, $90 \%$ after 6 weeks, $87.2 \%$ after 6 months, $86.7 \%$ after one year. In terms of continence rates, the MicroGYNious sling shows similar results compared to the established procedures. Therefore, this sling provides a good treatment option for the stress urinary incontinence. These good results must be confirmed in prospective randomized trials.
\end{abstract}

\section{Introduction}

Stress urinary incontinence affects up to $35 \%$ of women ${ }^{1}$ and the rate is likely to increase over the next years. This is due to a rising birth rate, a rising life expectance, an increase number of adipose women as well as the removal of taboos regarding incontinence. Women dare to speak about their complaints and are open for a treat- ment. Colposuspension and tension free vaginal tapes have been shown to be effective in treating patients with stress incontinence. Currently, the tension free vaginal tapes have been the mainstay of treatment for female stress urinary incontinence over the last decade. According to the metaanalysis of the European Association of Urology, the subjective cure rate is $75 \%$ after 12 months. ${ }^{2}$ However, there are adverse events and risks going along with this surgery including bladder and even bowel injury, groin pain and hematoma, and others. The critical statements of the FDA as well as the National Health Service regarding vaginal meshes gave reason to discuss the application of meshes in the urogynecology society in Germany. Therefore, a register will be set up to register the implants and document complications in order to further the implants and to increase patient satisfaction. So far, tension free vaginal tapes are still the gold standard for the treatment of the stress urinary incontinence in Germany.

The goal to develop these tapes further has led to the development of single incision slings in an effort to maintain efficacy while eliminating some of the side effects. Therefore, so called 'single incision slings' or 'mini slings' were developed in 2006 and released to the market. They are designed to be shorter than standard tension free vaginal tapes and do not penetrate the tissues as deeply. It was therefore thought that they would cause fewer side effects while being no less effective. So far, studies have focused on single incision slings including TVT-Secur, MiniArc, Ajust, Needleless, Tissue Fixation System and Ophira slings and others. ${ }^{3}$ One challenge in all studies is the difference in the fixation systems of these slings. While some surgeons simply rely on tissue in-growth into the porous mesh to hold them in place, others use anchors or other fixation mechanisms to anchor them to tissue. Beside that they are fixed either in the obturator membrane, in the pubourethral ligament inferior to the pubic symphysis or in the paraurethral tissue. The MicroGYNious single incision sling is placed in the paraurethral tissue with the anchors (Figure 1). Over the recent years, the use of the single incision slings has been increasing worldwide, as numerous observational cohort studies have shown minimal complications, quick recovery and 1-year efficacy within the range 85 $90 \%{ }^{4}$ Up until now, no study has been conducted to evaluate the outcome of the MicroGYNious sling. Therefore, we evaluated the effectiveness of the MicroGYNious incision sling in females for the treatment of stress urinary incontinence. The analyze is a
Correspondence: Sabine Schütze, Department of Gynaecology and Obstetrics University Ulm, Prittwitzstrasse 43, 89075 Ulm, Germany.

Tel.: 0049.731.500.58581

E-mail: sabine.schuetze@uniklinik-ulm.de

Key words: MicroGYNious; single incision sling; stress urinary incontinence; minimal invasive.

Acknowledgements: The authors would like to thank the department of Obstetrics and Gynecology, Alb-Doanu Klinikum Ehingen (Germany) for the database.

Contributions: SS: Manuscript writing, Data collection; UG: Data collection, examination; EM: Data collection. FS: Data analysis; WJ: Manuscript editing; MD: Project development.

Conflict of interest: SS, FS, EM and WJ declare that they have no conflict of interest. MD as well as UG have already done consulting work on behalf of the company A.M.I.

Availability of data and materials: All data generated or analyzed during this study are included in this published article.

Ethics approval and consent to participate: The Ethics Committee of Ulm approved this study $(232 / 18)$. The study is conformed to the Helsinki Declaration of 1964, as revised in 2013, concerning human and animal rights.

Informed consent: Written informed consent was obtained from a legally authorized representative(s) for anonymized patient information to be published in this article.

Received for publication: 6 May 2020.

Revision received: 3 March 2021.

Accepted for publication: 16 March 2021.

This work is licensed under a Creative Commons Attribution NonCommercial 4.0 License (CC BY-NC 4.0).

(C) Copyright: the Author(s), 2021

Licensee PAGEPress, Italy

Urogynaecologia 2021; 33:249

doi:10.4081/uij.2021.249

follow up early postoperatively, after 6 weeks, 6 months, one year, two years and it is ongoing.

\section{Materials and Methods}

This retrospective analysis was carried out on 115 patients who received a MicroGYNious single incision sling as a treatment for stress urinary incontinence at 
a regional hospital between 2015-2018. The operation was performed by an experienced surgeon. The MicroGYNious single incision sling consists of the sling and two anchors on both sides (Figure 1). The material is made of polypropylen. For the detailed operation technique see below.

The following parameters were recorded: degree of incontinence preoperatively, continence rate postoperatively and a follow-up after 6 weeks, 6 months, one year, two years and three years. The number of lost to follow-up was after 6 weeks $24(\mathrm{n}=$ 91), after 6 months $15(\mathrm{n}=100)$, after 6 months $37(\mathrm{n}=78)$, after one years $55(\mathrm{n}=$ $60)$, after two years $95(\mathrm{n}=20)$ and after three years 107 patients $(n=8)$. In order to make a clinically reliable statement, only the data up to one year postoperative were included in the analysis. At each point of time the participants received a clinical examination, including ultrasound, and a clarification regarding the stress urinary incontinence. This included the cough test and anamnestic information about the grade of stress urinary incontinence. Following definition of the grade of incontinence was used. i) Grade 1: urine loss during coughing, sneezing, pressure and laughing; ii) Grade II: urine loss during lifting, running and climbing the stairs; iii) Grade III: urine loss during standing without physical activity. ${ }^{5}$ Besides that, the age and the BMI of the patients, the postoperative pain on day 1-3 and the duration of the surgery were recorded. To record the pain the visual analog pain scale was used. This scale ranges from 1 (hardly any pain) - 10 (worst pain). During the clinical examination, particular attention was paid to mesh erosion. However, the existing IUGA/ICS classification of prosthesis-related complications was not used. This is based on the fact that this classifica- tion was not well known when the study was carried out. In the future, this has to be taken into account when comparing data dealing with prosthesis material.

In $2.6 \%$ only a MicroGYNious sling was used (therapy 1), in $60 \%$ a MicroGYNious sling together with a repair of the anterior wall was conducted (therapy 2 ), in $22.6 \%$ cases a MicroGYNious sling together with a repair of the anterior wall, a posterior repair (therapy 3 ) as well as a bilaterale sacrospinale colposuspension mesh was conducted, and in $14.8 \%$ an additional hysterectomy was performed (therapy 4). The study protocol was submitted to and approved by the ethics committee of the University of Ulm.

\section{Operational technique}

i) Sagittal incision in the region of the anterior vaginal wall immediately below the middle third of the urethra. Length of incision: 1.0 and $1.5 \mathrm{~cm}$; ii) Preparing the pouch for the insertion of the sling (Figure 1) using a forceps and small Metzenbaum scissors. Preparation is performed immediately below the anterior vaginal wall in direction of the paraurethral tissue towards the inferior ramus of the pubis bone. When the endopelvic fascia is reached, a short incision is performed on the left and on the right side. When pulling the scissors out, open them a bit in order to prepare the xing bed for the sling; iii) Seize one end of the sling using a fine forceps and insert it into the prepared pouch. The anchor (Figure 1) placed at the ends of the sling is used to hold it in place. Caution: Any possible required correction of the sling position must be performed immediately. The sling is kept in place independently in the paraurethral tissue; iv) Position the second end of the sling as described. Caution: The sling should have loose, tender contact below the urethra; v) Final check: a) for the loose fit of the sling below the urethra; $b$ ) for cessation of bleeding; vi) Continuous suture of the incision.

\section{Statistical analysis}

Data analysis was performed with IBM SPSS Statistics (V24) and Microsoft Excel (V15.2). Demographic characteristics are described as mean and standard deviation. Rates were reported as percents of valid cases at different times. Correlation analysis were conducted between the different therapies and the continence rate postoperative; between the continence rates 6 weeks, 6 month and one year postoperative; the stated pain and the duration of the surgery.

A logistic regression analysis was carried out to evaluate the postoperative incontinence rate in correlation with the respective therapy as well as to evaluate the preoperative incontinent grade and the postoperative outcome.

\section{Results}

The average BMI was 28.1 (standard deviation 4,112) and the average age was 63.8 (standard deviation 13,14) years in our study population. Preoperatively, grade I incontinence was rated in $6.1 \%$, grade II in $35.7 \%$, and grade III in $58.3 \%$ of the women in our study cohort. The continence rate postoperatively was $96.7 \%$, after 6 weeks $90 \%$, after 6 months and $87.2 \%$, after one year $86.7 \%$ (Figure 2). In $2.6 \%$ only a MicroGYNious sling was used (therapy 1), in $60 \%$ a MicroGYNious sling together with a repair of the anterior wall was conducted (therapy 2 ), in $22.6 \%$ cases a
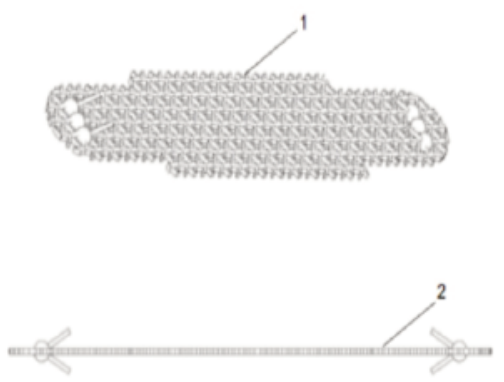

Figure 1. The MicroGYNious single incision sling.

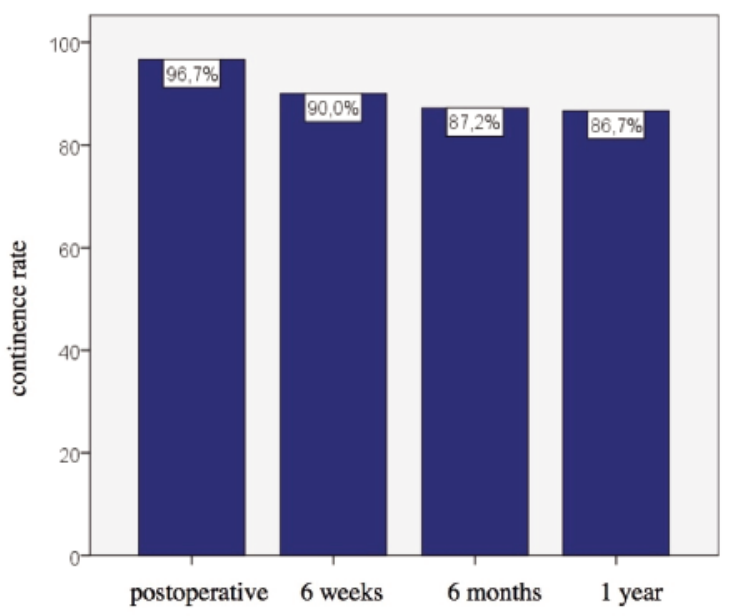

Figure 2. Distribution of the continence rate (\%) postoperative, 6 weeks, 6 months and one year postoperatively. 
MicroGYNious sling together with a repair of the anterior wall, a posterior repair (therapy 3) as well as a bilaterale sacrospinale colposuspension mesh was conducted, and in $14.8 \%$ an additional hysterectomy was performed (therapy 4). Therefore, the average duration of the surgery varied in relation to the mentioned treatments. Therapy 1: 20 minutes (standard deviation 4,2); therapy 2: 22.5 minutes (standard deviation 13,3); therapy 3: 50.4 minutes (standard deviation 31,1); therapy 4: 55.7 minutes (standard deviation 22,7).

No correlation was found between the continence rate 6 weeks (p: 1.000), 6 months (p: 0.502) and 1 year postoperative (p: 0.364) and the different therapies. For this analysis, the immediate postoperatively incontinence rate was excluded, due to a high continent rate (only three women had an incontinence) as well as the results of therapy 1 , as the number of treated women was very small in this group (3 women).

Besides that, a comparison between the incontinence rate after 6 weeks compared with 6 months was conducted. An improvement over the time could be demonstrated. $44,4 \%$ of the women with an incontinence after 6 weeks showed an improvement after 6 months. The other way around, $7.4 \%$ with no incontinence after 6 weeks developed an incontinence after 6 months (Figure 3, Figure 4).

Fifty percent out of all patients with incontinence after 6 weeks were continent after one year (Figure 4). The other way around, $9.4 \%$ of the patients developed incontinence during this time period.

The comparison between 6 month and one year showed an improvement of $14.3 \%$ and a worsening in $3.8 \%$ of the cases.

A logistic regression analysis was carried out to evaluate the postoperative incontinence rate in correlation with the respective therapy. No significant results could be shown. In addition, another logistic regression analysis was conducted to evaluate the preoperative incontinent grade and the postoperative outcome. Again, no significant results could be shown. Besides that, the average sensation of pain was raised on day 1-3 using the visual analog pain scale. Looking at all forms of therapy, on day one an average pain score of 2.1 was reported, on day two of 1.6 and on day three 1.3. However, significant correlations between the pain and the duration of the surgery could be shown (Figure 5) (day one, two and three $\mathrm{p}<0.001)$. A net erosion was reported in 4 cases $(3.5 \%)$ and a de novo urge in $5.2 \%$ of the women. No bladder injury, pain or hematoma was recorded.

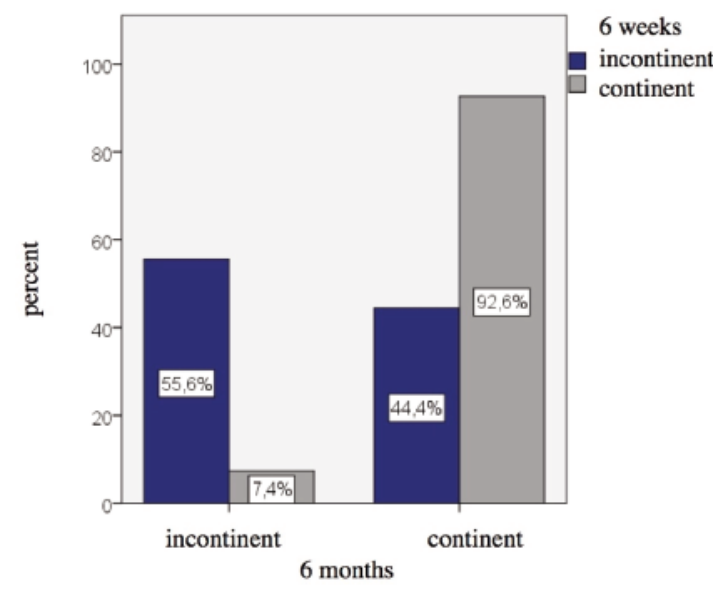

Figure 3. A comparison between the incontinence (blue) and continence rates (grey) after 6 weeks and 6 months ( $\mathrm{x}$ axis) in percent $(\%) .44,4 \%$ of the women with an incontinence after 6 weeks showed an improvement after 6 months. $7.6 \%$ with no incontinence after 6 weeks developed an incontinence after 6 months.

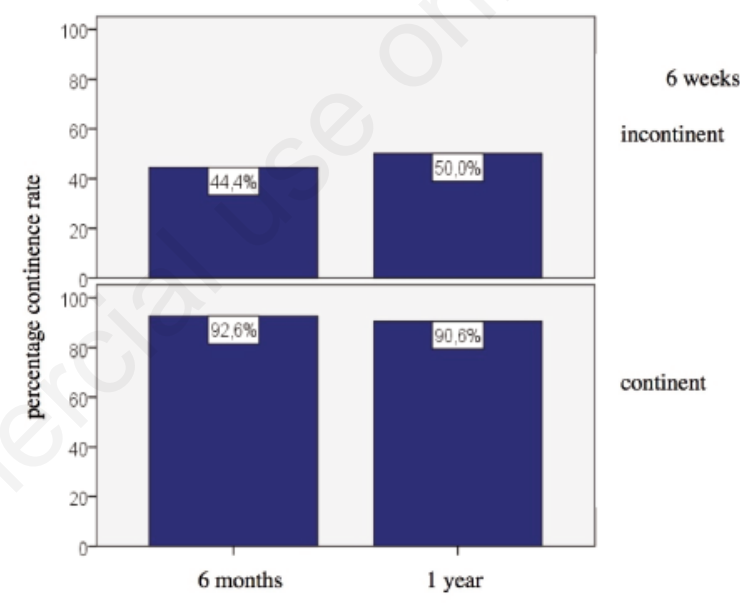

Figure 4. This shows the development of the continence rate between 6 weeks, 6 months and one year. Out of all patients with incontinence after 6 weeks $44,4 \%$ were continent after 6 months and $50 \%$ after one year. After 6 months $92,6 \%$ were continent, after 1 year $90,6 \%$.

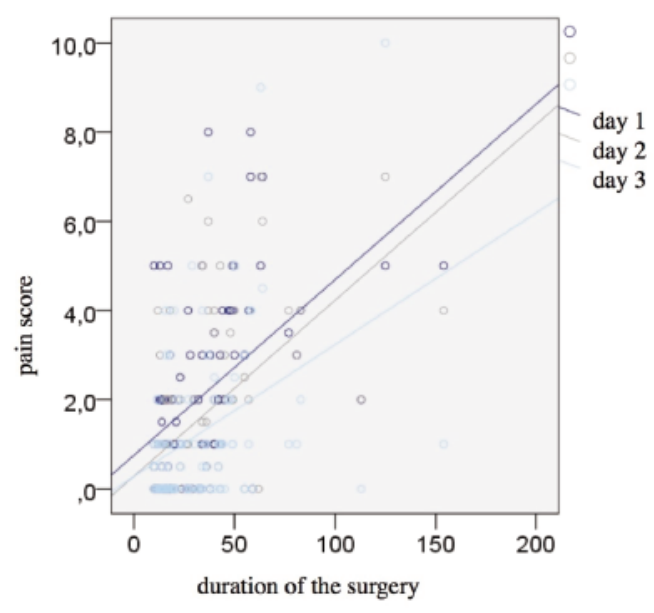

Figure 5. Significant correlations between the postoperative pain score and the duration of the surgery. The longer the duration of the surgery the higher is the postoperative pain score. 


\section{Discussion}

So far, studies have focussed on just a few single incision slings, including among others TVT-Secur, MiniArc, Ajust, Needleless, Tissue Fixation System and Ophira slings. ${ }^{3}$ So far, no study has been published evaluating the MicroGYNious single incision sling. Therefore, this study was initiated in order to gain knowledge about the outcome. This includes the effects as well as the side effects, especially in combination procedure in case a pelvic organ prolapse.

In our study the continence rate was $96.5 \%$ immediately postoperatively, $90 \%$ after 6 weeks, $87.2 \%$ after 6 months and $86.7 \%$ after one year (Figure 2). The continence rate in this study is going along with the results of other single incision slings. ${ }^{6-8}$ This is comparable with the standard therapy with a tension free vaginal tape. In the literature, the success rate for the retropubic tension free vaginal tape was reported with $77-80 \%$ after $5-11$ years. ${ }^{9,10}$ Ford et al. stated, that there was moderate quality evidence that up to 1 year the rate of subjective cure for the transobturator tension free vaginal tape ranges from $62 \%$ to $98 \%$ and for the retropubic tension free vaginal tape from $71 \%$ to $97 \% .^{11}$ Thus, the here investigated MicroGYNious single incision sling shows comparable success rates. This leads to the conclusion that this sling offers a good therapy option. In contrast to that, conflicting results according the other single incision slings are also published. Basu et al. showed a higher number of adverse events after using the Miniarc single incision sling. The study compared the threeyears-outcome of the single incision sling compared to the retropubic tension free vaginal tape. The overall 3-year failure rate was quite different in that study. $52.6 \%$ for the single incision surgery and $9 \%$ for the retropubic tension free vaginal tape surgery. ${ }^{12}$ This is in accordance with the review of Nambiar et al. They stated that the rate of cure of incontinence for single incision slings was worse compared to the standard therapy. Besides that, it is more likely to develop a de novo urgency. ${ }^{3}$

In our study, no significant correlation between the different therapies and the outcome, defined as the continent rate, was found. This supports the effectiveness of the MicroGYNious single incision sling especially in cases of a combined procedure.

Besides that, an improvement of the continence rate over time could be demonstrated. An improvement of 50\% was shown between 6 weeks and one year (Figure 4). This underlines the importance of long follow-ups in order to compare the long-term outcomes between the different therapies. Between 6 weeks and 6 months the continence rate increased in $44,4 \%$ of the patients (Figure 3, Figure 4) and between 6 weeks and one year in 50\% (Figure 4).

This study was able to show, that the postoperative result is not depending on the preoperative grade of the incontinence. Therefore, this therapy seems to be successful both in mild and severe cases.

Looking at the postoperative pain, as expected, a reduction over the postoperative days could be demonstrated. Figure 5 shows the relationship between the stated pain and the duration of the surgery. The longer the duration of the surgery the higher is the pain score. The goal of the single incision slings is to shorten the duration of the surgery in order to reduce the postoperative pain, the medication, the inpatient stay and the anesthetic risks, while maintaining the effectiveness. Abdel-Fattah et al. compared the single incision slings with the standard tension free vaginal tapes. They, as well as other studies, showed a shorter operation time and a lower pain score. ${ }^{3,13-15}$ The lower pain score of the single incision slings goes along with Oliveira et al. ${ }^{13}$ However, studies are still missing, which compare the outcome and the duration of single incision sling insertion with the standard therapies.

In some cases, adverse events after the insertion of the MicroGYNious sling occured. A net erosion was shown in 3.5\% and a de novo urgency in $5.2 \%$ of the women in our study cohort. Here conflicting literature in terms of adverse events after the tension free vaginal tape procedure can be found. For the transobturator and the retropubic tension free vaginal tape Ford et al. showed an overall rate of vaginal tape erosion or exposure or extrusion at 24 per 1.000 instances $(2.4 \%)$ with transobturator and 21 per $1.000(2.1 \%)$ for retropubic tension free vaginal tape. ${ }^{11}$ They demonstrated lower number of net erosions compared to our results. This could be either influenced by our small study cohort or this is due to our surgery procedure. Abdel-Fattah et al. reported a higher rate of revision surgery and a higher de novo incontinence after the insertion of a single incision sling. ${ }^{14}$ Though, in our study neither bladder perforation nor massive hemorrhage occurred, as described by Song et al. ${ }^{16}$ Therefore, larger studies are necessary to focus on the adverse events and to weight them against each other.

However, the development of a de novo urgency in our study is even lower compared to the standard therapy. Segal et al. reported a de novo urgency incidence of $4,3 \%$ and de novo POP incontinence of $9,1 \%$ after operation in pure stress urinary incontinence patients after the insertion of a tension free vaginal tape. ${ }^{17}$ An even higher number of de novo urgency after the standard therapy showed Lleberia-Juano's et al. They determined the frequency of de novo urgency after tension free vaginal tape compared with the transobturator tension free vaginal tape. That study reports a de novo urgency for both surgical procedures in $13,4 \%$ of the patients after 6 months, in $19,3 \%$ after 12 months and in $22,1 \%$ of the cases after 26 months. ${ }^{18}$

In conclusion, comparing the adverse events of the MicroGYNious single incision sling with the standard therapy neither a bladder perforation nor a massive hemorrhage occurred. A slightly higher amount of net erosion was shown and an equal to less amount of de novo urgency occurred. This might be due to an accurate tightening system of the MicroGYNious single incision sling without an over-elevation that we consider a major cause of de novo urgency.

However, a weakness of our study is the small number of patients, the absence of a control group as well as the different conducted therapies. Besides that, it is quite difficult to compare the single incision slings due to the fact, that they provide significant difference in the fixation systems. While some surgeons simply rely on tissue in-growth into the porous mesh to hold them in place, others use anchors or other fixation mechanisms to anchor them to tissue. Beside that they are fixed either in the obturator membrane, in the pubourethral ligament inferior to the pubic symphysis or in the paraurethral tissue. Therefore, prospective randomized trials are necessary, comparing every single incision sling with the standard therapy, including long followups.

In summary, the MicroGYNious single incision sling shows comparable results, especially in combined intervention with POP surgery, compared to the continence rate after the insertion of tension-free vaginal tapes and represents a good therapy option. It is a safe and an effective surgical procedure for the treatment of stress urinary incontinence.

\section{References}

1. Luber KM. The definition, prevalence, and risk factors for stress urinary incontinence. Rev Urol 2004;6:S3-9.

2. Thüroff JW, Abrams P, Andersson K-E, Artibani W, Chapple CR, Drake MJ, et al. EAU Guidelines on Urinary Incontinence. Eur Urol 2011;59:387400 .

3. Nambiar A, Cody JD, Jeffery ST. 
Single-incision sling operations for urinary incontinence in women. Cochrane Database Syst Rev 2014;CD008709.

4. Kennelly MJ, Moore R, Nguyen JN, et al. Prospective Evaluation of a Single Incision Sling for Stress Urinary Incontinence. J Urol 2010;184:604-9.

5. Dannecker C, Friese K, Stief C, Bauer $\mathrm{R}$. Urinary incontinence in women: part 1 of a series of articles on incontinence. Dtsch Arztebl Int 2010;107:420-6.

6. Naumann G, Albrich S, Skala C, et al. Single-Incision Slings (SIS) - a New Option for the Surgical Treatment of Female Stress Urinary Incontinence. Geburtsh Frauenheilk 2012;72:125-31.

7. Enzelsberger H, Cemer I, Enzelsberger S, Schalupny J. MiniArc ${ }^{\circledR}$ versus Monarc ${ }^{\circledR}$ - Eine prospektiv randomisierte Vergleichsstudie zur operativen Therapie der weiblichen Stressharninkontinenz. Geburtsh Frauenheilk 2010;70:499-502.

8. Kennelly MJ, Moore R, Nguyen JN, et al. Miniarc ${ }^{\circledR}$ single-incision sling for treatment of stress urinary incontinence: 2-year clinical outcomes. Int Urogynecol J 2012;23:1285-91.

9. Ward KL, Hilton P, UK and Ireland TVT Trial Group. Tension-free vaginal tape versus colposuspension for pri- mary urodynamic stress incontinence: 5-year follow up. BJOG: Int J Obstet Gynaecol 2007;115:226-33.

10. Nilsson CG, Palva K, Rezapour M, Falconer C. Eleven years prospective follow-up of the tension-free vaginal tape procedure for treatment of stress urinary incontinence. Int Urogynecol J 2008; 19:1043-7.

11. Ford AA, Rogerson L, Cody JD, et al. Mid-urethral sling operations for stress urinary incontinence in women. Cochrane Incontinence Group, editor. Cochrane Database Syst Rev 2017;7:CD006375.

12. Basu M, Duckett J. Three-year results from a randomised trial of a retropubic mid-urethral sling versus the Miniarc single incision sling for stress urinary incontinence. Int Urogynecol J 2013;24:2059-64.

13. Oliveira R, Botelho F, Silva P, Resende A, Silva C, Dinis P, et al. Exploratory Study Assessing Efficacy and Complications of TVT-O, TVT-Secur, and Mini-Arc: Results at 12-Month Follow-Up. Eur Urol 2011;59:940-4.

14. Abdel-Fattah M, Ford JA, Lim CP, Madhuvrata P. Single-Incision MiniSlings Versus Standard Midurethral Slings in Surgical Management of
Female Stress Urinary Incontinence: A Meta-Analysis of Effectiveness and Complications. Eur Urol 2011;60:46880.

15. Gaber ME, Borg T, Samour H, et al. Two new mini-slings compared with transobturator tension-free vaginal tape for treatment of stress urinary incontinence: A 1-year follow-up randomized controlled trial. J Obstet Gynaecol Res 2016;42:1773-81.

16. Song PH, Kwon DH, Ko YH, Jung HC. The Long-Term Outcomes of the Tension-free Vaginal Tape Procedure for Treatment of Female Stress Urinary Incontinence: Data from Minimum 13 Years of Follow-Up. Low Urin Tract Symptoms 2017;9:10-4.

17. Segal JL, Vassallo B, Kleeman S, et al. Prevalence of Persistent and De Novo Overactive Bladder Symptoms After the Tension-Free Vaginal Tape. Obstet Gynecol 2004;104:1263-9.

18. Lleberia-Juanós J, Bataller-Sánchez E, Pubill-Soler J, et al. De novo urgency after tension-free vaginal tape versus transobturator tape procedure for stress urinary incontinence. Eur J Obstet Gynecol Reprod Biol 2011;155:22932. 